logical triggers, such as a hormonal pregnancy test ${ }^{15}$ or a viral infection..$^{16}$ The study by Smithels $e t$ al, ${ }^{17}$ although it was not a controlled trial and used multivitamin supplementation, would seem to indicate the possible success of dietary improvement.

We conclude, therefore, that dietary counselling was effective in south Wales. All eight recurrences were in mothers whose diet was poor during the early stages of the project pregnancy. Counselling may have reduced the incidence of recurrence by $60 \%$, but even more effective counselling may be possible.

Advice on diet should be part of a health education programme that should start in school. Women should be taught what is an adequate and balanced diet and how important such a diet is, especially before and during pregnancy. As the dietary habits of a woman are determined largely by what she learns in the parental home, ${ }^{18}$ however, to be effective any dietary advice would have to be reinforced by the press and the media. In the case of women at increased risk of pregnancy complicated by neural-tube defects because of a history of such pregnancies or because a close relation has a neural-tube defect, special dietary counselling may be required well before any pregnancy is begun.

We thank the women who took part in this study. This study was supported by Action Research for the Crippled Child, the Manpower Services Commission, and Tenovus.

Requests for reprints should be addressed to Professor $\mathrm{K} M$ Laurence, Department of Child Health, Welsh National School of Medicine, Heath Park, Cardiff CF4 4XN.

\section{References}

${ }^{1}$ Record, RG, McKeown T. Congenital malformations of the central nervous system 1-survey of 930 cases. Br 7 Prev Soc Med 1949;3: 183-219.

${ }^{2}$ Williamson EM. Incidence and family aggregation of major congenital malformations of the central nervous system (a survey of 100 families in Southampton). 7 Med Genet $1965 ; 2: 161-72$.

3 Laurence KM, Carter CO, David PA. Major central nervous system malformations in South Wales. II. Pregnancy factors, seasonal variation, and social class effects. $\operatorname{Br} \mathcal{F}$ Prev Soc Med 1968;22:212-22.

${ }^{4}$ Carter CO, Evans K. Spina bifida and anencephalus in Greater London. 7 Med Genet 1973;10:209-34.

${ }^{5}$ Elwood JM, Elwood JH. Epidemiology of anencephalus and spina bifida. Oxford: Oxford University Press, 1980.

${ }^{6}$ Smithells RW, Sheppard S, Schorah CJ. Vitamin deficiencies and neural tube defects. Arch Dis Child 1976;51:944-50.

7 Richards IDG. Congenital defects in South Wales. PhD thesis. University of Wales. 1971

${ }^{8}$ Department of Health and Social Security. Recommended intake of nutrients for the United Kingdom. Reports on Public Health and Medical Subjects; Great Britain. 1969; No 120.

${ }^{9}$ Carter CO, David PA, Laurence KM. A family study of central nervous system malformations in South Wales. $\mathcal{f}$ Med Genet 1968;5:81-106.

${ }^{10}$ Carter CO. Clues to the aetiology of neural tube malformations. Dev Med Child Neurol 1974;16,suppl 32:3-15.

11 Thiersch JB. Therapeutic abortions with folic acid antagonist 4-amniopteroylglutamic acid (4 amino PGA) administered by the oral route. Am F Obstet Gynecol $1952 ; 63: 1298-304$.

${ }^{12}$ Andrews J, McGarry JM. A community study of smoking in pregnancy. fournal of Obstetrics and Gynaecology of the British Commonwealth 1972; 79:1057-73.

${ }^{13}$ Choi NW, Klaponski J. Neural tube defects: an epidemiological elicitation of etiological factors. Neurology (Minneap) 1970;20:399-400.

${ }^{14}$ Kelsey JL, Dwyer T, Holford TR, Bracken MB. Maternal smoking and congenital malformations. F Epidemiol Community Health 1978;32: 102-7.

15 Gal I, Kiman B, Sterm J. Hormonal pregnancy tests and congenital malformation. Nature 1967;216:83.

${ }^{16}$ Saxén K, Hjelt L, Sjöstedt JE, Hakosalo J, Hakosalo H. Asian influenza during pregnancy and congenital malformations. Acta Pathol Microbiol Scand 1960;49:114-26.

17 Smithels RW, Sheppard S, Schorah CJ, et al. Possible prevention of neural tube defects by periconceptional vitamin supplementation. Lancet $1980 ; \mathrm{i}: 339-40$.

18 Emanuel I, Sever LE. Questions concerning the possible association of potatoes and neural tube defects and an alternative hypothesis relating to maternal growth and development. Teratology $1974 ; 8: 317-2 n$

(Accepted 20 October 1980)

\title{
Adjuvant chemotherapy for breast cancer: side effects and quality of life
}

\author{
B V PALMER, G A WALSH, J A MCKINNA, W P GREENING
}

\section{Summary and conclusions}

In a trial of postoperative adjuvant chemotherapy women with primary breast cancer and spread to one or more axillary nodes were randomised to receive a six-month course of either the single agent chlorambucil or the five-drug combination of chlorambucil, methotrexate, fluorouracil, vincristine, and adriamycin. On completing the treatment 47 patients were asked to fill in questionnaires at home on the side effects of treatment and its influence on the quality of their life. Side effects including nausea, vomiting, malaise, and alopecia had been severe enough to interfere with their lifestyle in $9(42 \%)$ of the patients who had received the single agent and $19(79 \%)$ of those who had received

Breast Unit, Royal Marsden Hospital, London SW3 6JJ

B V PALMER, FRCS, senior surgical registrar (present address: Royal Sussex County Hospital, Brighton)

G A WALSH, secretary of unit

J A MCKINNA, FRCS, consultant surgeon

W P GREENING, FRCS, consultant surgeon multiple-drug treatment. Various other side effects were reported by a few patients. Seven (29\%) of the patients who had received the multiple-drug schedule voluntarily added that the treatment had been "unbearable" or "could never be gone through again."

The proportion of patients who had experienced severe side effects while receiving the treatment was considerable; hence such adjuvant chemotherapy is justifiable only if it will substantially improve a patient's prognosis.

\section{Introduction}

Results of using adjuvant chemotherapy after mastectomy for patients with primary breast cancer encouraged the hope that chemotherapy might be a major advance in the treatment of these patients. ${ }^{1-4}$ Various trials were set up to establish the most effective regimens and assess which patients might be helped. Thus Bonadonna et $a l^{5}$ and Fisher et $a l^{6}$ showed little benefit in postmenopausal patients. Results of most studies indicated that the toxicity of the various drug regimens was not troublesome. 
A trial of adjuvant chemotherapy was started at this hospital in 1975 and a survey undertaken to discover the true incidence and severity of the various side effects experienced by women in the trial.

\section{Patients and methods}

Patients at this hospital who had undergone mastectomy for carcinoma of the breast with spread to one or more axillary lymph nodes were entered into the trial and randomised to receive one of two schedules of adjuvant chemotherapy so that single- and multipledrug treatment could be compared. Results of screening tests for metastases were negative in all cases. Patients allocated to schedule 1 received only chlorambucil, $25 \mathrm{mg}$ by mouth at night for five nights. Patients allocated to schedule 2 received adriamycin, vincristine, fluorouracil, methotrexate, and chlorambucil. On day 1 they received in the outpatient department adriamycin $40 \mathrm{mg}$, vincristine $1 \mathrm{mg}$, and 5 -fluorouracil (5-FU) $500 \mathrm{mg}$ intravenously and methotrexate $100 \mathrm{mg}$ intramuscularly and at 2000 took chlorambucil $25 \mathrm{mg}$ and chlorpromazine $50-100 \mathrm{mg}$ by mouth; and at 0800 on day 2 they took metoclopramide (Maxolon) $10 \mathrm{mg}, 5-\mathrm{FU} 500 \mathrm{mg}$, and folinic acid $30 \mathrm{mg}$ by mouth

Both schedules were repeated every three weeks subject to satisfactory haematological control. Both were administered on an outpatient basis over six months, eight courses being given at three-weekly intervals. Nausea and vomiting were anticipated and antiemetics prescribed to accompany both drug schedules. Of the antiemetics prescribed, metoclopramide appeared to be less effective than drugs such as prochlorperazine (Stemetil) and perphenazine (Fentazin). For geographical and social reasons a few women receiving the multiple-drug regimen were admitted overnight.

When they had completed the eight courses of treatment the patients were asked to answer a detailed questionnaire to elicit the side effects of their treatment and their overall reactions. One of us (GAW) passed out the questionnaires and explained their format. Patients were asked to complete the form at home and return it by post. No obvious difficulties were encountered in answering the questions. The forms were handed to 47 patients, of whom 23 had received schedule 1 and 24 schedule 2 . All 47 forms were completed and returned, but some patients did not answer every question. Patients were asked whether they had experienced a particular symptom and, if so, when it had started, how long it had lasted, and whether it had changed with successive courses of treatment. To each question four or five answers were possible: the patient indicated which answer she thought was most relevant by marking a box opposite that answer. After each question a space was left in which the patients were asked to write any additional specific comments.

\section{Results}

\section{MAJOR SIDE EFFECTS}

Nausea-Table I shows the severity of nausea experienced, its time of onset, and whether it had improved with subsequent courses of the drugs. On average, nausea lasted for the five days of treatment with the single agent and for three to five days when the combined drugs were used.

Vomiting-Table II gives details of the severity and time of onset of vomiting. Vomiting was not always associated with nausea. Some patients vomited for several days after each course and "any exertion" and the "slightest smell" were common precipitating factors. One woman who had taken schedule 1 commented, "The vomiting was so unpredictable and so severe it was not possible to go out socially for nine days out of each twenty-one."

Alopecia was by far the most emotive side effect associated with the treatment and had to be fully discussed with those patients randomised into schedule 2 before they started treatment (table III). Appreciable hair loss had occurred in the group receiving schedule 2 from one to eight weeks after the start of treatment. All the women in this group had been offered NHS wigs before starting treatment and most had accepted, although several, especially the younger women, preferred to purchase their own as they did not like the range of colours and styles. Many did not find it easy wearing a wig; one stated: "I found it was hot and felt everyone knew I was wearing a wig." Several complained that, although the wig had fitted before treatment, with appreciable hair loss it became too loose and was therefore liable to blow off or slip around. Regrowth of hair usually occurred within six months after stopping treatment, and, although it was sometimes of a different texture and colour, the women were generally pleased with their "new" hair.

Feeling "off colour"-A peculiar malaise had affected most patients to some extent at each course of treatment (table IV). One eloquent patient, who had received schedule 2, wrote: "No words describe the sensation you euphemistically call 'off colour,' which starts about an hour or less after the injection. The unpleasant sensation crawls round the body. It feels as though one has had an anaesthetic that has not properly worked, only it is worse than that-vile."

TABLE I-Number (\%) of patients with varying degrees of nausea, its time of onset, and whether its severity changed with subsequent courses of treatment

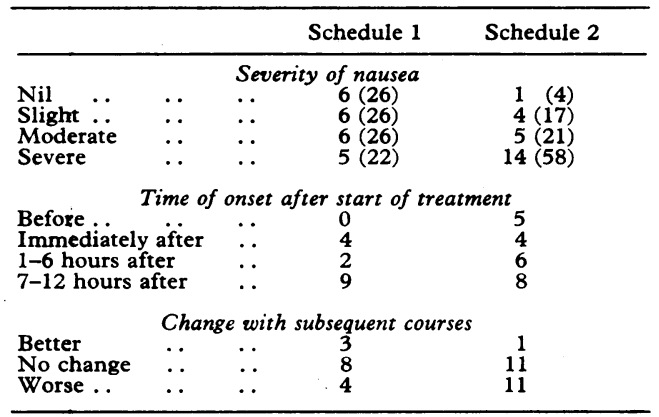

TABLE II-Numbers (\%) of patients who vomited, time of onset of vomiting, and whether its severity changed with subsequent courses of treatment

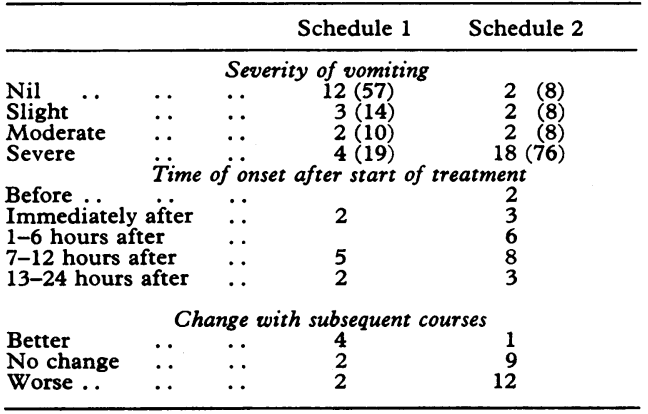

TABLE III-Number (\%) of patients with alopecia and time of onset after start of treatment

\begin{tabular}{|c|c|c|c|}
\hline & & Schedule 1 & Schedule 2 \\
\hline $\begin{array}{l}\text { None .. } \\
\text { Slight . } \\
\text { Considerable } \\
\text { Total .. }\end{array}$ & $\begin{array}{l}\cdots \\
\cdots \\
\cdots\end{array}$ & $\begin{array}{l}\text { Severity of alopecia } \\
\ldots \\
\therefore \\
\therefore\end{array}$ & $\begin{array}{r}1(4) \\
3(13) \\
16(70) \\
3(13)\end{array}$ \\
\hline $\begin{array}{l}2-3 \text { weeks } \\
4-5 \text { weeks } \\
6-7 \text { weeks } \\
\geqslant 8 \text { weeks }\end{array}$ & $\begin{array}{l}\because \\
\because \\
\therefore\end{array}$ & \begin{tabular}{lc}
\multicolumn{2}{c}{ Time of onset } \\
$\ldots$ & 1 \\
$\therefore$ & 2 \\
$\ldots$ & 2
\end{tabular} & $\begin{array}{l}5 \\
4 \\
5 \\
6\end{array}$ \\
\hline
\end{tabular}

\section{MINOR SIDE EFFECTS}

Mouth ulcers had been a troublesome symptom for many patients receiving schedule 2 (see table $\mathrm{V}$ ); the ulcers developed within 24 hours of treatment and lasted, on average, for seven days after each course. Most patients had had mouth ulcers with each course, the severity changing little with successive courses, although some complained of ulceration with only one or two courses.

Taste-Only three patients who had received schedule 1 compared with 12 who had received schedule 2 had noticed an abnormal sense of taste. Several patients remarked specifically that the taste of tea or coffee was "horrible" or "made them feel ill." One patient commented that "everything became tasteless"; another that "food and drink tasted sweet"; and a third that "all liquids tasted vile."

Smell-Ten of the patients who had received schedule 2 remarked 
on an abnormal sense of smell, of whom five had noticed an increased sensitivity. Only one patient who had received schedule 1 , however, had been aware of any change. One patient who had received schedule 2 stated that her sense of smell had become so acute that it had made life difficult: for two out of three weeks she could not drive a car because of the fumes, and she could not bear anyone smoking near her for a few days after each course of treatment.

TABLE IV-Number (\%) of patients feeling "off colour," duration of malaise, and changes with subsequent courses of treatment

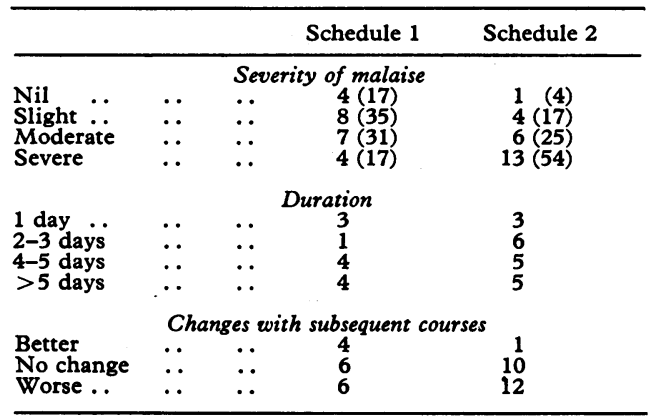

TABLE V-Numbers (\%) of patients with minor side effects of varying severity

\begin{tabular}{|c|c|c|c|}
\hline & & Schedule 1 & Schedule 2 \\
\hline $\begin{array}{l}\text { None ... } \\
\text { Slight ... } \\
\text { Moderate } \\
\text { Severe }\end{array}$ & $\begin{array}{l}\ddot{ } \\
\ddot{ } \\
\cdots\end{array}$ & \begin{tabular}{cr}
\multicolumn{2}{c}{ Mouth ulcers } \\
$\ldots$ & $18(79)$ \\
$\ldots$ & $3(13)$ \\
$\ldots$ & 1 \\
. & $14(4)$
\end{tabular} & $\begin{array}{r}6(25) \\
5(21) \\
1(4) \\
12(50)\end{array}$ \\
\hline $\begin{array}{l}\text { None ... } \\
\text { Slight ... } \\
\text { Moderate } \\
\text { Severe }\end{array}$ & $\begin{array}{l}\because \\
\because \\
\cdots\end{array}$ & 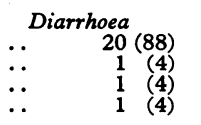 & $\begin{array}{r}16(67) \\
5(21) \\
3(12)\end{array}$ \\
\hline $\begin{array}{l}\text { None ... } \\
\text { Slight .. } \\
\text { Moderate } \\
\text { Severe }\end{array}$ & $\begin{array}{l}\because \\
\because \\
\cdots\end{array}$ & 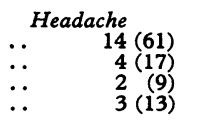 & $\begin{array}{r}15(62) \\
4(17) \\
1(4) \\
4(17)\end{array}$ \\
\hline \multicolumn{4}{|c|}{ 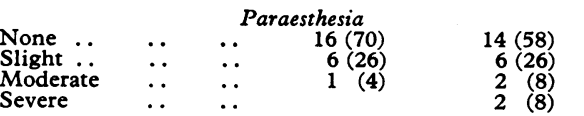 } \\
\hline
\end{tabular}

TABLE VI-Responses of patients to the question "How much did the full course of treatment interfere with your life?" (Figures are numbers (\%) of patients responding)

\begin{tabular}{lcccc}
\hline & & \multicolumn{2}{c}{ Schedule 1 } & Schedule 2 \\
\hline Not at all & $\ldots$ & $\ldots$ & $\mathbf{6}(29)$ & $1(4)$ \\
Slightly & $\ldots$ & $\ldots$ & $6(29)$ & $4(17)$ \\
Moderately & $\ldots$ & $\ldots$ & $7(33)$ & $10(42)$ \\
Severely & $\ldots$ & $\ldots$ & $2(9)$ & $9(37)$ \\
\hline
\end{tabular}

Appetite-Twelve of the women who had received schedule 1 had noted a change in appetite; of these, eight had had a reduced and four an increased appetite. Thirteen who had received schedule 2 had noticed a reduction and three an increase in appetite.

Indigestion had been noted by 11 women in each group but had been severe in only two, both receiving schedule 2 . One of these stated: "My stomach felt like a ball of fire two days after treatment."

Diarrhoea (see table V)-Two patients who had received schedule 1 had had diarrhoea, which occurred within 12 hours after starting treatment and continued for a few days. Four women who had received schedule 2 complained of diarrhoea: it occurred within 12 hours after starting treatment and was of only a few hours' duration. Three women noted that it started before treatment. One patient who had received schedule 1 and three who had received schedule 2 complained of constipation during the six months of treatment.
Menstruation-Of the 10 women still menstruating when given schedule 1 , three had become amenorrhoeic. Of the 16 premenopausal women who had received schedule 2 , seven noted no change; in four the periods had become irregular, and in five they had stopped completely.

Cystitis-Frequency and dysuria had been noted by two patients when receiving schedule 1 but had been slight in both. Six patients who had received schedule 2 noted these symptoms, which had been severe in only one.

Bone pain-Six women who had received schedule 1 and four who had received schedule 2 complained of skeletal discomfort within a few hours after drug administration; this symptom had been severe in only one patient in each group. In none was there any evidence of osseous deposits on bone scanning or $x$-ray examination.

Headache (see table V) was not a prominent feature of treatment. In patients receiving schedule 1 headaches had tended to last for five days and their intensity appeared to vary little with successive courses. In the group receiving schedule 2 headaches had lasted for only one to two days but half the patients thought the severity had increased with each course.

"Pins and needles" (table V) had been noted most frequently in the hands: it was usually transient but was maximal some days after treatment.

Blurred vision, which was distinct from conjunctivitis, had been noted by five patients taking schedule 1 and 10 taking schedule 2 .

Conjunctivitis-"Sore" eyes were a major source of complaint of patients who had received schedule 2 , being noted by 18 patients. Conjunctivitis had been severe in four of these patients, two of whom had stopped treatment after six courses because of its severity. Conjunctivitis had been present in four patients receiving schedule 1 . Profuse watering and irritation would start seven to 10 days after treatment and last for seven days or more. It prevented one woman wearing her contact lenses.

Skin changes had been noted by nine women receiving schedule 1 and 11 receiving schedule 2 . Most complained of excessively dry and sometimes flaky skin but one in each group had developed rashes that were exacerbated by sunlight. Two women who had received schedule 2 volunteered the information that minor cuts and abrasions had healed slowly and become easily infected.

Nails had been brittle and easily broken in five patients receiving schedule 1 and nine receiving schedule 2 .

Other symptoms-One patient added that she had been prone to infections and had had persistent coryza. She had developed pneumonia, throat infections, enteritis, and styes and had had severa septic cuts while taking schedule 2 .

\section{INTERFERENCE WITH QUALITY OF LIFE}

Patients were asked to what extent the treatment had disturbed their lives. Table VI shows their replies.

At the end of the survey form a space had been left for further comments, and, as was to be expected, reactions were far stronger from the group who had received schedule 2 . Seven patients $(29 \%)$ stated that "treatment was unbearable" or "never again," with a further eight $(33 \%)$ volunteering that the experience had been "most unpleasant" or that they had "dreaded" the treatment "but would have it again if it were recommended for their health's sake."

\section{Discussion}

This survey shows the severity of some patients' reactions to cytotoxic drugs. Undoubtedly side effects were accentuated by the anxiety and depression experienced by many of the patients, who had recently undergone a major mutilating operation, had a possibly fatal tumour, and had been attending hospital every three weeks to receive drugs with upsetting side effects. Importantly, of the 24 women receiving Schedule 2 five $(22 \%)$ experienced nausea and two $(9 \%)$ actually vomited before the drugs were administered.

Adjuvant chemotherapy may be unpleasant and for the patient has no immediate objective benefit. The side effects are due to the differing drugs used and the methods of administration. The manner in which information on toxicity is obtained is highly relevant in assessing the severity of side effects: it had been apparent that a few questions asked by a doctor in a busy 
outpatient clinic did not elicit a true picture of morbidity. The possibility that the doctor and being in a clinic inhibit a patient's inclination to report side effects led us to produce a questionnaire and to arrange for a sympathetic, non-medical member of the team to distribute and explain it. The women were asked to complete the form at home in the hope that they would then express their reactions to the treatment more accurately.

We recommend that this method is a more appropriate one of assessing side effects, and similar experiences were reported by $\mathrm{H}$ Bush at a symposium of the Royal College of Physicians, London, in May 1980. If such questionnaires were more widely used the toxicity of various chemotherapy regimens could be compared more objectively.

Troublesome side effects were much more common and severe in those women receiving the five-drug regimen, and the therapeutic case for using such a combination has to be a strong one. Side effects were also seen in an appreciable number of patients receiving single-agent chemotherapy, and claims that single-agent chemotherapy (using chlorambucil in this dosage) should be used as an adjuvant because it is "non-toxic" should therefore be regarded with caution.

The proportion of patients who had experienced severe side effects in the trial was considerable; hence such treatment is justifiable only if it will result in a substantial increase in prognosis. A major ambition of doctors should be to improve the wellbeing of patients. Any treatment which causes distress or illness should be given only when there is good evidence of future benefit. The results of this survey contributed to our decision to stop this study of adjuvant chemotherapy.

We are grateful to Miss Rosemary Fisher for her valuable advice in designing the questionnaire and thank the patients for their help and interest.

Requests for reprints should be sent to Miss G A Walsh, Secretary, Breast Unit, Royal Marsden Hospital, Fulham Road, London SW3 6JJ.

\section{References}

1 Fisher B, Carbone P, Economou SG, et al. L-Phenylalanine mustard (L-Pam) in the management of primary breast cancer. $N$ Engl $\mathcal{F}$ Med 1975 ;292:117-22.

2 Bonadonna G, Brusamolino E, Valagussa P, et al. Combination chemotherapy as an adjuvant treatment in operable cancer. $N \mathrm{Engl} \mathrm{f} \mathrm{Med}$ $1976 ; 294: 405$.

${ }^{3}$ Anonymous. Major advance in breast cancer therapy. $N$ Engl $\mathcal{f}$ Med $1976 ; 294: 440$.

${ }^{4}$ Anonymous. Treating breast cancer-true light or false dawn ? Br Med $\mathcal{f}$ 1976 ;ii :263.

${ }^{5}$ Bonadonna G, Rossi A, Valagussa $P$, et al. The CMF program for operable breast cancer with positive axillary nodes: updated analysis on the disease-free interval, site of relapse and drug tolerance. Cancer $1977 ; 39: 2904-15$.

${ }^{6}$ Fisher B, Glass A, Redmond C, et al. L-Phenylalanine mustard (L-Pam) in the management of primary breast cancer: an update of earlier findings and a comparison with those utilizing L-PAM plus 5-fluorouracil (5-FU). Cancer 1977;39:2883-3903.

(Accepted 22 October 1980)

\title{
Prophylaxis of infection after appendicectomy: a survey of current surgical practice
}

\author{
W B CAMPBELL
}

\section{Summary and conclusions}

Two hundred and eighty questionnaires were sent to junior surgical staff throughout England inquiring about their use of systemic antibiotic prophylaxis, topical antibacterial agents, and surgical drainage in appendicectomy. One hundred and seventy-five $(63 \%)$ replies were received from 81 of the 87 hospitals included in the survey. Prophylactic systemic antibiotics were used by 78 surgeons $(46 \%)$ when operating on a normal appendix but by $168(99 \%)$ when the organ had perforated. Most surgeons started antibiotics before operation, but proportionately fewer did so when the appendix was gangrenous or perforated. Patients with severe contamination tended to receive longer courses of antibiotics, although the duration of administration varied considerably. Metronidazole was included in over $95 \%$ of all the prophylactic regimens and was often combined with other drugs when the appendix was gangrenous and perforated. Topical antibacterial agents were applied to the wound routinely by only 45 surgeons (26\%), although 106

\footnotetext{
Department of General Surgery, Frenchay Hospital, Bristol BS16 1LE

W B CAMPBELL, MRCP, FRCS, registrar in surgery (present appointment: surgical registrar, University Department of Surgery, Bristol Royal Infirmary, Bristol BS2 8HW)
}

(61\%) used them sometimes. Povidine-iodone was the agent most commonly used. Only 98 surgeons (56\%) ever drained appendicectomy wounds, while 135 (77\%) sometimes drained the peritoneal cavity.

Evidence suggests that present methods of giving systemic antibiotic prophylaxis should continue, but that topical agents and surgical drainage are perhaps unnecessary when surgeons are confident of the efficacy of the systemic treatment used.

\section{Introduction}

Over the past 20 years many reports have assessed different methods of reducing infection after appendicectomy. The techniques examined have included surgical drainage, the application of topical agents to the wound, and the administration of prophylactic systemic antibiotics. Although the general principle of systemic prophylaxis is now well established, opinion seems to vary widely regarding which patients require antibiotics, the optimum time to start the drugs, and the duration of administration. Furthermore, topical agents are still commonly used, although whether they confer much benefit compared with systemic drugs is not entirely clear.

The impact on everyday surgical practice of results of studies on antibiotics in appendicectomy has not been assessed. I therefore sent 280 questionnaires to junior surgical staff asking for details of the prophylactic measures used in their unit to prevent infection after appendicectomy. 